\title{
Annual rhythms of milk synthesis in dairy herds in 4 regions of the United States and their relationships to environmental indicators
}

\author{
I. J. Salfer, $\odot$ P. A. Bartell, $\odot$ C. D. Dechow, $\odot$ and K. J. Harvatine* ${ }^{\circ}$ \\ Department of Animal Science, Pennsylvania State University, University Park 16802
}

\section{ABSTRACT}

The annual rhythms of milk and milk component yields are not well described and are important to dairy management. Recent analysis of federal milk marketing orders in the United States observed that the amplitude and time at peak (acrophase) of the rhythms of milk fat and protein concentration differ among regions, but the rhythms of milk and milk component yields are not well described. Our objective was to determine the annual rhythms of milk and milk component production from 4 US regions at the herd level and examine potential environmental factors entraining these rhythms. Monthly Dairy Herd Improvement Association records of all available herds in Pennsylvania (PA), Minnesota $(\mathrm{MN})$, Texas (TX), and Florida (FL) from the years 2003 to 2016 were obtained from Dairy Records Managements Systems. Milk yield, fat and protein yield, and fat and protein concentration were fit to the linear form of the cosine function with a 12-mo period using a linear mixed effects model. Additionally, the fit of models containing either the cosine function or environmental temperature were compared using an $F$-test. Milk yield and fat and protein yields and concentrations fit a cosine function in all 4 states, indicating an annual rhythm. The amplitude (peak to mean) of the rhythm of milk yield varied by state and was lower in PA (1.2 kg) and MN (1.2 kg) compared with TX $(3.1 \mathrm{~kg})$ and $\mathrm{FL}(3.3 \mathrm{~kg})$. Fat and protein yields similarly showed greater amplitudes in the southern versus northern states. The amplitudes of the rhythms of fat and protein concentration were opposite by region, with greater amplitudes occurring in $\mathrm{MN}$ and $\mathrm{PA}$ than in TX and FL. The acrophases of milk yield and milk fat and protein yields and concentrations also varied by state, but all peaked between October and March. An annual rhythm fit the data better than changes in environmental temperature for all responses in all

Received July 30, 2019.

Accepted December 13, 2019.

*Corresponding author: kjh182@psu.edu states, except for fat and protein concentrations in FL, which exhibited lower amplitude seasonal rhythms. The yearly pattern of milk yield closely followed the fixed yearly pattern of the day to day changes in day length, whereas the rhythms of milk fat and protein concentrations followed the yearly pattern of absolute day length. Results suggest that the region of the United States in which a herd is located affects their annual rhythms of production, with a greater yearly variation in milk, fat, and protein yields occurring in the southern United States. The consistency of annual rhythms across years and herds allowed development of regression equations to adjust expectations across the year to account for the annual rhythm.

Key words: annual rhythm, milk synthesis, seasonality, photoperiod

\section{INTRODUCTION}

Circannual rhythms commonly occur in nature as a mechanism for animals to anticipate and adapt to seasonal changes in their environment before they occur. These rhythms drive remarkable biological changes including migration, hibernation, and seasonal reproduction. The change in photoperiod across the year is a primary synchronizer of annual rhythms for organisms living in temperate climates. For example, in short day breeders like sheep, estrus is triggered as photoperiod shortens, resulting in mid-spring lambing (Woodfill et al., 1991). True circannual rhythms are endogenously generated and persist even when animals are placed under constant photoperiods. An extremely robust example of a circannual rhythm is observed in African stonechats (Saxicola torquatus axillaris), a species of Old World flycatcher. When hatched in the laboratory and held in a constant $12.25 \mathrm{~h}$ of light:11.75 h of dark photoperiod, stonechats exhibited circannual rhythms of molt, migration, and testicular growth for $15 \mathrm{yr}$ (Gwinner, 1996). Recent evidence suggests that specialized cells within the hypothalamus integrate changes in photoperiod using a molecular circadian clock, causing time-of-year-specific signals that can be maintained even under fixed photoperiods (Hazlerigg et al., 2018). 
Dairy cattle display seasonal changes in milk production that are well appreciated by dairy producers and nutritionists. We have previously characterized annual rhythms of milk components using USDA milk market data and milk and milk component yield using test-day data from 1684 cows in 11 Pennsylvania (PA) dairy herds (Salfer et al., 2019). Fat and protein concentration peaked near early January in all regions within the USDA milk market data set. However, the amplitudes varied by region with southern regions having a lower amplitude rhythm than northern regions. Moreover, cow-level data revealed that milk yield peaked in late March and fat and protein yields peaked in late February in herds in PA and that neither parity nor diacylglycerol O-acyltransferase 1 (DGAT1) K232A polymorphism, associated with most the genetic variation in milk fat concentration, exert substantial influence over annual rhythms of production (Salfer et al., 2019).

Developing an improved understanding of the factors influencing annual rhythms of milk synthesis will allow dairy producers to better predict the production potential of their herd and aid diagnosis of suboptimal production and component levels. Furthermore, determining the relationships between these rhythms and environmental indicators may help identify potential physiological mechanisms responsible for generating these rhythms. The objective of this study was to model the annual rhythms of milk and milk fat and protein yield and milk fat and protein concentration using a robust data set containing a large number of herds in northern and southern states. The hypotheses were that the annual rhythms of milk production would vary by latitude, with Florida (FL) and Texas (TX) having lower amplitude rhythms than PA and Minnesota (MN) and that day length would be a better predictor than temperature for these rhythms.

\section{MATERIALS AND METHODS}

\section{Data Collection}

Monthly DHIA test-day records from January 2004 to October 2016 were obtained from Dairy Records Management Systems (DRMS) for all available herds in FL, MN, PA, and TX. These states were selected because they represented 4 distinct geographic regions of the United States and had a large amount of data available within the DRMS. Test-day records included the average milk, fat, and protein yield of all lactating cows within each of the DHIA tests. Fat and protein concentration were calculated by dividing their yield by milk yield. Researchers were blind to herd name, and records included test date, herd size, average DIM, percent of cows in first, second, and third or greater lactation, milk yield, fat concentration, protein concentration, and SCC. All herds with fewer than 10 lactating cows were removed from the data set. For comparisons among states, data were filtered to include only herds designated as having Holsteins to eliminate the potentially confounding effects of breed. A total of 764,196 records from 9,757 Holstein herds were included in the data set $(5,021$ records from 98 herds in FL, 184,521 records from 2708 herds in MN, 552,542 records from 6,647 herds in PA, and 15,825 records from 303 herds in TX).

\section{Cosinor Rhythmometry}

The fit, amplitude, and time at peak of a 12-mo rhythm was determined among selected states and breeds using cosinor rhythmometry as described by Salfer et al. (2019). Briefly, response variables were fit to the linear form of cosine functions with a 12-mo period in ASREML version 4.1 with the following model:

$$
\begin{aligned}
& y_{i j k l m}=\mu+S_{i}+A_{j}+B_{k}+S_{i} \times A_{j}+S_{i} \times B_{k}+M_{l}+Y_{m} \\
& +H_{o}+\varepsilon_{i j k l m o}
\end{aligned}
$$

where $y_{i j k l m}$ is the response variable of interest, $\mu$ is the overall mean, $S_{i}$ is the fixed effect of state, $A_{j}$ is the linear form of the sine function, $B_{k}$ is the linear form of the cosine function, $M_{l}$ is the fixed effect of average days in milk, $Y_{m}$ is the random effect of year $(m=2004$ to 2016), $H_{o}$ is the random effect of herd, and $\varepsilon_{i j k l m o}$ is the residual error. The fit of the linear form of cosine functions was compared with a reduced model testing the linear effect of day of year:

$$
y_{i j k l}=\mu+S_{i}+D_{j}+S_{i} \times D_{j}+M_{k}+Y_{l}+H_{o}+\varepsilon_{i j k l},[2]
$$

where $y_{i j k l}$ is the response variable of interest, $\mu$ is the overall mean, $S_{i}$ is the fixed effect of state, $D_{j}$ is the fixed effect of day of year ( $j=1$ to 365$), M_{k}$ is the fixed effect of average days in milk, $Y_{l}$ is the random effect of year $(l=2004$ to 2016$), H_{o}$ is the random effect of herd, and $\varepsilon_{i j k l}$ is the residual error. The fit of the annual rhythms was determined by a zero amplitude test comparing the residual sums of squares between the full model containing linearized cosine functions and the reduced model (Cornelissen, 2014). The amplitude (peak minus mean) and acrophase (time at peak) and their significance tests were determined using a script written in $\mathrm{R}$ version 3.4 .3 according to equations of Bourdon et al. (1995). 


\section{Effect of Breed on Annual Rhythms of Production}

The effect of breed was tested based on breed designation codes in the database. Breed designations were listed for herds that contained $75 \%$ or more of a particular breed, with herds containing less than $75 \%$ of any one breed included in the crossbred/mixed group. Breeds within fewer than 50 herds were removed, leaving Holsteins ( $\mathrm{n}=8,790$ herds, 675,068 records), Jerseys ( $\mathrm{n}=398$ herds, 21,510 records), Brown Swiss (n $=67$ herds, 2,913 records), and crossbred $/$ mixed $(\mathrm{n}=$ 14,63 herds; 53,444 records). A full model containing the fixed effects of breed, cosine terms, the interaction of breed with cosine terms, and average days in milk and the random effects of year, state, and herd was compared with a reduced model containing the fixed effects of breed, day of year, and average days in milk, and the random effect of year.

\section{Comparison of Annual Rhythm with Temperature}

To compare the fit of the annual rhythm with the fit of a model testing the effect of environmental temperature, daily climate data were collected from the US National Weather Service from representative weather stations centrally located near heavy populations of dairy herds in each state (Tallahassee, FL; Litchfield, MN; Harrisburg, PA, Abilene, TX). The effect of daily maximum temperature on milk and milk fat and protein yield and milk fat and protein concentration was tested using the following model:

$$
y_{i j k l}=\mu+S_{i}+T_{j}+S_{i} \times T_{j}+M_{k}+Y_{l}+\varepsilon_{i j k l},
$$

where $y_{i j k l}$ is the response variable of interest, $\mu$ is the overall mean, $S_{i}$ is the fixed effect of state, $T_{j}$ is the maximum daily temperature, $M_{k}$ is the fixed effect of average days in milk, $Y_{l}$ is the random effect of year $(l=2004$ to 2016$)$, and $\varepsilon_{i j k l}$ is the residual error. The coefficient of determination $\left(\mathbf{R}^{2}\right)$ was calculated for both the model containing cosine functions with a 12 mo period (Equation 1) and the model with maximum temperature (Equation 3). An F-test was performed to compare the fit of the 2 models (Glatting et al., 2007).

\section{RESULTS}

\section{Annual Rhythms Within Selected States}

An interaction between state (PA, MN, TX, and FL) and the cosine function with a 12-mo period occurred for milk and milk fat and protein yield and milk fat and protein concentration so the fit, amplitude, and acrophase of the rhythm were determined for each state $(P$
$<0.001)$. Average milk yield was greatest in PA (31.1 $\mathrm{kg})$, followed by MN $(30.7 \mathrm{~kg})$, TX $(30.1 \mathrm{~kg})$, and FL $(27.2 \mathrm{~kg} ; P<0.001)$. In all 4 states, milk yield fit the 12 -mo cosine function, indicating the presence of an annual rhythm $(P<0.001$; Figure 1A). The amplitude of the 12-mo rhythm of milk yield differed by state, with FL $(2.1 \mathrm{~kg})$ and TX $(1.8 \mathrm{~kg})$ having amplitudes almost twice that of PA $(1.2 \mathrm{~kg})$ and $\mathrm{MN}(1.2 \mathrm{~kg} ; P<0.001)$. The acrophase, or day at peak, occurred latest in MN (April 22), followed by PA (April 15) and did not differ between FL (April 9) and TX (April 7; $P>0.10$ ).

Milk fat and protein concentrations also fit an annual rhythm in all states $(P<0.002$; Figure $1 \mathrm{C}$ and $1 \mathrm{E})$. The amplitude of the milk fat rhythm differed by state, being greatest in $\mathrm{MN}(0.17 \%)$, similar in $\mathrm{PA}$ and $\mathrm{TX}$ $(0.14 \%)$, and lowest in FL $(0.12 \% ; P<0.05)$. However, acrophase did not differ by state with all acrophases occurring between January 1 and January $5(P>0.10)$. Unlike milk fat concentration, the annual rhythm of milk protein concentration differed among regions, with FL having a lowest amplitude $(0.06 \%)$, followed by PA $(0.09 ; P<0.001)$, with no difference in amplitude occurring between MN $(0.10 \%)$ and TX $(0.11 \% ; P>$ $0.10)$. The acrophase of the protein rhythm was similar between MN, PA, and TX, with all occurring within 3 d of December 20, whereas FL had an acrophase occurring $19 \mathrm{~d}$ earlier on December 1.

The yearly variations in milk yield and milk fat and protein concentrations produced 12-mo rhythms in milk fat and protein yields regardless of state, with differences in amplitude and acrophase across states $(P<$ 0.001; Figures 1B and 1D). The amplitude of the milk fat yield rhythm was greatest in cows from TX $(71 \mathrm{~g})$ and FL (67 g), with lower amplitudes observed in PA $(59 \mathrm{~g})$ and MN (45 g). The acrophase of the 12-mo rhythm of milk fat yield occurred later in FL (March 31) and TX (March 13) than in MN (February 27) and PA (February 23; $P<0.001$ ). The annual rhythm of milk protein yield did not differ in amplitude between FL (57 g) and TX (55 g), but rhythms from both states oscillated with a higher amplitude than those in PA $(35 \mathrm{~g})$ and $\mathrm{MN}$ (33 g; $P<0.001)$. The acrophase of protein yield peaked later in FL (March 31) than in MN (March 3), TX (March 3), and PA (March 1; $P<$ $0.001)$.

\section{Annual Rhythms Among Breeds}

Annual rhythms were detected for milk and milk fat and protein yields and milk fat and protein concentrations regardless of breed $(P<0.001)$. As expected, average milk yield was greatest for Holsteins $(30.9 \mathrm{~kg})$, followed by Brown Swiss $(26.1 \mathrm{~kg})$, crossbred/mixed $(25.6 \mathrm{~kg})$, and Jerseys (20.9 kg; $P<0.05$; Figure $2 \mathrm{~A})$. 
A
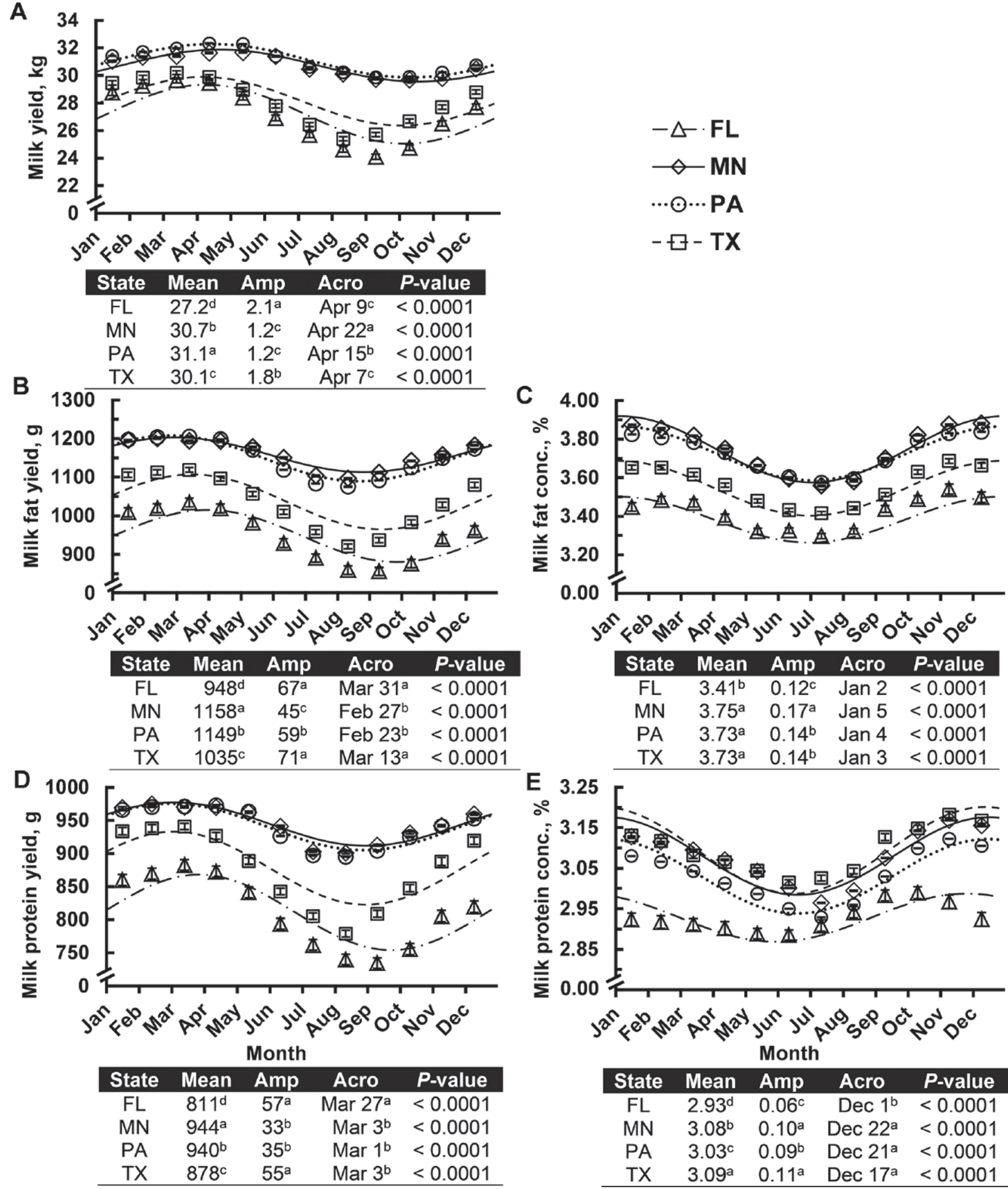

Figure 1. Annual rhythms of milk, fat, and protein yield and fat and protein concentration in Holstein dairy herds in Florida (FL), Minnesota (MN), Pennsylvania (PA), and Texas (TX). Data include DHIA test-day results from individual herds in FL (98 herds, 5,021 records), MN (2,708 herds, 184,521 records), PA (6,647 herds, 552,542 records), and TX (303 herds, 15,825 records) acquired from Dairy Records Management Systems. Panels show (A) effect of state on annual rhythms of milk yield, (B) effect of state on annual rhythms of fat yield, (C) effect of state on annual rhythms of fat concentration. (D) effect of state on annual rhythms of protein yield. (E) effect of state on annual rhythms of protein concentration. conc. = concentration. Data are presented as the LSM of each month, with error bars representing the SEM and the line as the fitted cosine function with a period of 12 mo. Cosinor analysis is shown below each panel and includes the amplitude (Amp; difference between peak and mean), acrophase (Acro; time at peak of the rhythm), and the $P$-value of the zero-amplitude test. Means, amplitudes, and acrophases that do not share a superscript $(\mathrm{a}-\mathrm{c})$ differ $(P<0.05)$. 
The amplitude of milk yield did not differ among Holsteins, Brown Swiss, or crossbred/mixed, but was $25 \%$ lower in Jerseys $(P<0.05)$. Breeds varied in acrophase of the annual rhythm of milk yield with Holsteins (April 16) peaking the earliest, followed by crossbred/mixed (April 20), Jerseys (May 4), and Brown Swiss (May 10). The annual rhythms of milk fat and protein concentration also varied by breed (Figures $2 \mathrm{C}$ and $2 \mathrm{E}$ ). Mean milk fat concentration was greatest in Jerseys (4.71\%), followed by Brown Swiss (4.07\%), crossbred/ mixed (3.96\%), and Holsteins (3.73\%). The amplitude of the annual rhythm of milk fat concentration was greatest in Jerseys $(0.27 \%)$, followed by Brown Swiss $(0.23 \%)$, crossbred/mixed $(0.20 \%)$, and was lowest in Holsteins $(0.15 \% ; P<0.05)$. All breeds had an acrophase of milk fat concentration that occurred between January 3 and January $7(P>0.05)$. Like milk fat concentration, the amplitude of protein concentration was lowest in Holsteins (0.09\%), but did not differ between Jerseys (0.15\%), crossbreed/mixed (0.15\%), and Brown Swiss (0.14\%). The acrophase of the protein concentration rhythm was similar among Holsteins (December 21), Jerseys (December 22), and crossbred/ mixed (December 22) and occurred 4 d later in Brown Swiss (December 26).

Milk fat yield was greatest in Holsteins $(1,148 \mathrm{~g} ; P$ $<0.05)$, followed by Brown Swiss (1,056 g), crossbred/ mixed (1,005 g), and was lowest in Jerseys (985 g; $P$ $<0.05)$. Similarly, milk protein yield was greatest in Holsteins (939 g), followed by Brown Swiss (874 g), crossbred/mixed (812 g), and Jerseys (747 g). The amplitude of milk fat yield differed among all breeds with Holsteins having the greatest amplitude (56 g), followed by crossbred/mixed ( $55 \mathrm{~g})$, Jerseys (52 g), and Brown Swiss (39 g; $P<0.05$; Figure 2B). The acrophase of fat yield did not differ by breed with all annual rhythms of milk fat yield peaking between February 26 and March $1(P>0.05)$. Holsteins (35 g) and crossbred/mixed (30 g) had the greatest amplitudes of milk protein yield, followed by Jerseys (26 g) and Brown Swiss (23 g; $P<$ $0.05)$. Protein yield did not differ by breed peaking on March 1, 2, 3, and 12 for Holsteins, crossbred/mixed, Jerseys, and Brown Swiss, respectively $(P<0.05$; Figure 2D).

\section{Comparison of Annual Rhythm and Temperature Models}

To compare the influence of environmental temperature versus the annual rhythm in photoperiod, a model containing the daily maximum temperature of a selected weather station in each state was compared with the cosine function with a period of 12 mo. Milk yield fit a 12-mo cosine function better than the model including the effect of maximum temperature $(P<$ 0.0001; Table 1). Moreover, within each the 4 states examined (FL, MN, PA, and TX), a cosine function fit the data better than the maximum temperature model $(P<0.0001)$. Model $\mathrm{R}^{2}$ was increased from 0.20 in the temperature model to 0.23 in the 12 -mo cosine model for the combined data set and $\mathrm{R}^{2}$ was also greater for the cosine function in all individual states. Data from FL (0.14 vs. 0.23$)$ and TX (0.32 vs. 0.40$)$ had the greatest improvements in model $\mathrm{R}^{2}$ from the temperature model to the cosine function model.

Fat concentration data fit a cosine function better than the temperature model in the combined data set $(P<0.0001)$ and for all individual states $(P<0.02$; Table 1). Model $\mathrm{R}^{2}$ of the combined data set was improved from 0.30 in the temperature model to 0.31 in the cosine model. Furthermore, the $\mathrm{R}^{2}$ of the cosine model was 0.01 units greater in MN, PA, and TX, but was the same for both models in FL. Milk protein concentration fit a 12-mo cosine function better than maximum temperature models in the combined data set and in data from MN, PA, and TX $(P<0.0001)$. However, milk protein concentration fit the model testing the effect of maximum temperature better than the model testing the cosine function in FL $(P<0.0001)$. Model $\mathrm{R}^{2}$ of milk protein concentration was improved from 0.29 in the temperature model compared with 0.25 in the cosine model in the combined data set. In data from individual states, the $\mathrm{R}^{2}$ of the model containing cosine functions was greater than that containing maximum temperature for protein concentration in all states.

Fat and protein yield also fit a cosine function better than temperature model for the combined model $(P<$ $0.0001)$ and each individual state $(P<0.0001)$. Model $\mathrm{R}^{2}$ of the combined data set was improved from 0.20 in the maximum temperature model to 0.22 in the cosine function model for fat yield and improved from 0.12 to 0.14 for protein yield.

\section{Regression Equations to Adjust for Seasonal Changes in Production}

The consistency of annual rhythms among years allows for the derivation of regression equations to adjust expected production for each month (Salfer et al., 2019). Equations derived from the linear form of the cosine function were used to predict actual milk and milk fat and protein yield and milk fat and protein concentration for each of the 4 regions (Table 2). The expected deviations from mean responses were computed from these equations for rapid adjustment of milk and milk fat and protein yield and milk fat and 

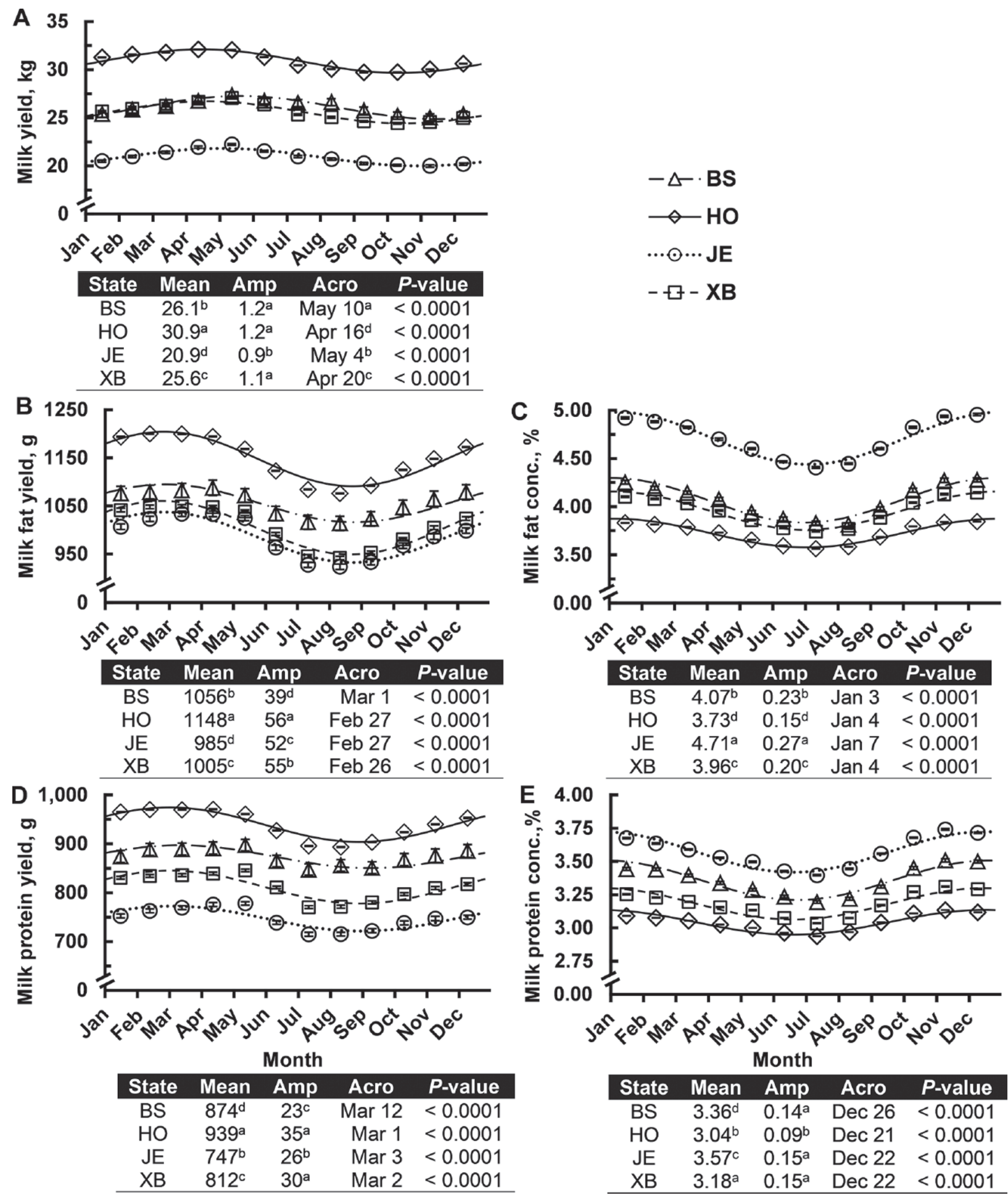

Figure 2. Annual rhythms of milk and milk fat and protein yield and milk fat and protein concentration by breed. Data include DHIA testday results from individual herds designated to contain Brown Swiss (BS; 67 herds, 2,913 records), Holsteins (HO, 8,790 herds, 675,071 records), Jerseys (JE; 398 herds, 21,510 records), and crossbred/mixed breed (1,463 herds, 53,444 records) acquired from Dairy Records Management Systems. Panels show (A) effect of breed on annual rhythms of milk yield, (B) effect of breed on annual rhythms of fat yield, (C) effect of breed on annual rhythms of fat concentration, (D) effect of breed on annual rhythms of protein yield, and (E) effect of breed on annual rhythms of protein concentration. conc. = concentration. Data are presented as the LSM of each month, with error bars representing the SEM and the line as the fitted cosine function with a period of 12 mo. Cosinor analysis is shown below each panel and includes the amplitude (Amp; difference between peak and mean), acrophase (Acro; time at peak of the rhythm), and the $P$-value of the zero-amplitude test. Means, amplitudes, and acrophases that do not share a superscript $(\mathrm{a}-\mathrm{d})$ differ $(P<0.05)$. 
protein concentration to account for the annual rhythm (Supplemental Tables S1 to S4; https://doi.org/10 $.3168 /$ jds.2019-17362).

\section{DISCUSSION}

Milk synthesis exhibited an annual rhythm in all 4 states representing different regions of the United States. In all states, milk yield peaked in mid-April, whereas fat and protein concentration peaked at the start of the year. These results were similar to previous accounts of seasonal variations in milk yield. Wood (1970) detected a "spring hump" in milk yield across multiple years, Bailey et al. (2005) determined that the maximal quantity of milk shipped per farm in the Mideast Federal Milk Market Order occurred in March, April, and May, and Salfer et al. (2019) observed that in 11 PA dairy herds, the yearly rhythm of milk yield peaked on March 13, whereas fat concentration peaked on January 25, and protein concentration peaked on December 20.

The amplitudes of annual rhythms of milk yield and composition varied by region. States in the southern United States (FL and TX) had greater amplitudes of milk and milk fat and protein yield, whereas FL had a lower amplitude of milk fat and protein concentration. These results concurred with those observed by Salfer et al. (2019), which demonstrated that the Milk Marketing Order located in FL had a lower amplitude of fat concentration than other orders. Together, these observations suggest that the amplitude of annual rhythms is directly influenced by the latitude, perhaps related to differences in photoperiod. In this experiment, all data were collected from the northern hemisphere where winter occurs in December through March and summer occurs from June to September. Data from the southern hemisphere may provide insight for better understanding of the relationship between photoperiod and

Table 1. Comparison between models testing the fit of a cosine function versus maximum temperature

\begin{tabular}{|c|c|c|c|c|}
\hline Item & $\begin{array}{l}\mathrm{R}^{2} \text { cosine } \\
\text { model }^{1}\end{array}$ & $\begin{array}{l}\mathrm{R}^{2} \text { temperature } \\
\text { model }^{2}\end{array}$ & $F$-value & $P$-value \\
\hline \multicolumn{5}{|c|}{ Milk yield, $\mathrm{kg} / \mathrm{d}$} \\
\hline Combined & 0.23 & 0.20 & $10,543.8$ & $<0.0001$ \\
\hline FL & 0.23 & 0.14 & 386.0 & $<0.0001$ \\
\hline $\mathrm{MN}$ & 0.16 & 0.14 & $1,781.2$ & $<0.0001$ \\
\hline $\mathrm{PA}$ & 0.19 & 0.16 & $8,172.9$ & $<0.0001$ \\
\hline \multirow{2}{*}{\multicolumn{5}{|c|}{ Fat yield, $\mathrm{g} / \mathrm{d}$}} \\
\hline & & & & \\
\hline Combined & 0.22 & 0.20 & $5,089.7$ & $<0.0001$ \\
\hline FL & 0.10 & 0.06 & 622.4 & $<0.0001$ \\
\hline MN & 0.15 & 0.14 & $4,323.7$ & $<0.0001$ \\
\hline $\mathrm{PA}$ & 0.19 & 0.17 & 222.8 & $<0.0001$ \\
\hline $\mathrm{TX}$ & 0.29 & 0.22 & $5,089.7$ & $<0.0001$ \\
\hline \multicolumn{5}{|c|}{ Protein yield, g/d } \\
\hline Combined & 0.14 & 0.12 & $24,667.1$ & $<0.0001$ \\
\hline FL & 0.24 & 0.10 & 33.1 & $<0.0001$ \\
\hline $\mathrm{MN}$ & 0.10 & 0.09 & $5,935.0$ & $<0.0001$ \\
\hline $\mathrm{PA}$ & 0.14 & 0.12 & $19,278.9$ & $<0.0001$ \\
\hline TX & 0.27 & 0.17 & 308.8 & $<0.0001$ \\
\hline \multicolumn{5}{|c|}{ Fat concentration, $\%$} \\
\hline Combined & 0.31 & 0.30 & $6,332.1$ & $<0.0001$ \\
\hline FL & 0.07 & 0.07 & 3.75 & 0.02 \\
\hline $\mathrm{MN}$ & 0.22 & 0.21 & $1,382.7$ & $<0.0001$ \\
\hline $\mathrm{PA}$ & 0.33 & 0.32 & $4,957.4$ & $<0.0001$ \\
\hline TX & 0.30 & 0.29 & 68.9 & $<0.0001$ \\
\hline \multicolumn{5}{|c|}{ Protein concentration, $\%$} \\
\hline Combined & 0.29 & 0.25 & 24.666 .6 & $<0.0001$ \\
\hline FL & 0.02 & 0.004 & -32.6 & $\mathrm{NS}^{3}$ \\
\hline MN & 0.28 & 0.22 & $5,934.6$ & $<0.0001$ \\
\hline PA & 0.29 & 0.24 & $19,278.5$ & $<0.0001$ \\
\hline $\mathrm{TX}$ & 0.19 & 0.17 & 308.6 & $<0.0001$ \\
\hline
\end{tabular}

${ }^{1}$ Cosine model: $y_{i j k l m}=\mu+S_{i}+A_{j}+B_{k}+S_{i} \times A_{j}+S_{i} \times B_{k}+M_{l}+Y_{m}+\varepsilon_{i j k l m}$, where $y_{i j k l m}$ is the response variable of interest, $\mu$ is the overall mean, $S_{i}$ is the fixed effect of state, $B_{k}$ is the linear form of the cosine function, $A_{j}$ is the linear form of the sin function, $M_{l}$ is the fixed effect of average days in milk, $Y_{m}$ is the random effect of year ( $m=2004$ to 2016), and $\varepsilon_{i j k l m}$ is the residual error.

${ }^{2}$ Temperature model: $y_{i j k l}=\mu+S_{i}+T_{j}+S_{i} \times T_{j}+M_{k} \times Y_{l}+\varepsilon_{i j k l}$, where $y_{i j k l}$ is the response variable of interest, $\mu$ is the overall mean, $S_{i}$ is the fixed effect of state, $T_{j}$ is the maximum daily temperature, $M_{k}$ is the fixed effect of average days in milk, $Y_{l}$ is the random effect of year $(l=2004$ to 2016$)$, and $\varepsilon_{i j k l}$ is the residual error.

${ }^{3} F$-test of temperature model fits data better than the cosine model $(P<0.0001)$. 
annual rhythms of milk synthesis; however, these data are limited and confounded by management system. In New Zealand, milk yield peaks in September through January, and fat and protein concentration peak from June through August (Auldist et al., 1998). This would suggest that annual rhythms of milk synthesis are opposite in the southern compared with the northern hemisphere. However, the cows were housed on pasture and results were likely affected by changes in pasture composition across the year and perhaps by seasonal breeding.

Of the 4 breeds examined, all displayed annual rhythms of production with few differences in the rhythms among breeds. Milk yield peaked approximately a half month later in Brown Swiss and Jerseys than Holsteins and crossbred/mixed, but this difference is unlikely to be biologically significant. All breeds studied were of the Bos taurus taurus subspecies, which were developed in northern Europe and are relatively genetically similar. A comparison between Bos taurus

Table 2. Equations for cosine regression equations for milk and milk fat and protein yield and milk fat and protein concentration for Florida (FL), Minnesota (MN), Pennsylvania (PA), and Texas (TX)

\begin{tabular}{lcc}
\hline & \multicolumn{2}{c}{ Cosine term $^{1}$} \\
\cline { 2 - 3 } Response & $\mathrm{A}$ & $\mathrm{B}$ \\
\hline Milk, kg & & \\
FL & -0.35 & 2.11 \\
MN & -1.17 & 1.08 \\
PA & -0.009 & 1.17 \\
TX & -2.10 & 1.74 \\
Fat, g & & \\
FL & -0.54 & 67.4 \\
MN & 23.2 & 37.8 \\
PA & 34.6 & 48.4 \\
TX & 17.4 & 69.0 \\
Protein, g & & \\
FL & 3.50 & 56.8 \\
MN & 14.7 & 29.2 \\
PA & 17.2 & 30.7 \\
TX & 25.2 & 49.0 \\
Fat, $\%$ & & \\
FL & 0.14 & 0.003 \\
MN & 0.17 & 0.014 \\
PA & 0.14 & 0.009 \\
TX & 0.14 & 0.006 \\
Protein, \% & & -0.029 \\
FL & 0.051 & -0.014 \\
MN & 0.095 & -0.016 \\
PA & 0.091 & -0.024 \\
TX & 0.104 & \\
\hline Coeffcists & & \\
\hline
\end{tabular}

${ }^{1}$ Coefficients derived from fitting DHIA test-day data acquired from Dairy Records Management Systems to a 12-mo cosine function with the following equation: $y=x-A \times \cos \left(\frac{2 \pi m}{12}\right)+B \times \sin \left(\frac{2 \pi m}{12}\right)$, where $x$ is the average value for each parameter within each state, $A$ is the coefficient of the cosine term $w, B$ is the coefficient of the sine term, and $m$ is the month of the year. A cosine by state interaction was included so coefficients could be derived within each state. Model $\mathrm{R}^{2}$ is presented in Table 1. taurus breeds and animals of the Bos taurus indicus subspecies, which were developed in tropical climates with a smaller change in in photoperiod throughout the year, would provide insight to understand the evolution of annual rhythms of production, but to our knowledge these data are not available. Chital (Axis axis), a species of deer native to the Indian subcontinent near the equator, show asynchronous annual rhythms of gonadal activity both in the wild and captivity, whereas these rhythms are well synchronized in related species of deer native to Europe (Loudon and Curlewis, 1988). Cattle from subspecies developed at different latitudes may similarly differ in their annual rhythms.

Seasonal declines in milk production are often attributed to heat stress. Heat stress occurs during mid to late summer because of high ambient temperature and humidity (West, 2003). Although heat stress has wellestablished effects on milk production, cow health, and reproduction, several factors suggest that additional factors influence the yearly variation in milk yield and components. First, we have clearly established that the yearly patterns of milk production fit a cosine function with a gradual increase and decrease throughout the year. Heat stress is considered an acute effect that occurs when the temperature-humidity index rises above 72 (Armstrong, 1994). If seasonal changes in milk production were due only to heat stress, we would expect to see reasonably stable milk production from fall through spring with a sharp decline during the summer when environmental temperatures and humidity rise. Additionally, the change would be expected to differ from year to year depending on severity and timing of heat stress. Furthermore, the nadir of milk yield occurs in early October, rather than in July when environmental temperature is greatest. Although there may be carryover effects of heat stress leading to depressed milk production into the fall, it is unlikely that this would cause milk yield to decrease below levels seen during acute heat stress. Interestingly, average milk, fat, and protein yields fall below the fitted cosine function for the months of June, July, and August, particularly in TX and FL. This additional depression could likely be due to heat stress during this time. The direct effect of heat stress has been investigated in heat chambers. Six published experiments measuring milk production in environmental chambers are summarized in Table 3. Milk yield was decreased by heat stress in all 6 experiments (average decrease of $6.7 \mathrm{~kg}$ ), fat concentration was increased by heat stress in 5 out of the 6 experiments (average increase of 0.22 percentage units), and protein concentration was decreased in 4 and increased in 2 experiments (average decrease of 0.12 percentage units). Notably, the effects of heat stress on milk fat concentration directly contradict the observed yearly 
Table 3. A summary of milk yield and milk fat and protein concentration responses in experiments testing the effects of heat stress in environmental chambers

\begin{tabular}{lrrc}
\hline Reference & Milk, kg & Fat, \% & Protein, \% \\
\hline Rhoads et al. (2009) & -10.6 & 0.34 & -0.13 \\
Shwartz et al. (2009) & -10.1 & 0.06 & -0.22 \\
Wheelock et al. (2010) & -9.6 & 0.60 & -0.27 \\
Zimbelman et al. (2010) & -0.1 & -0.17 & 0.13 \\
Baumgard et al. (2011) & -6.2 & 0.28 & -0.12 \\
Rungruang et al. (2014) & -3.4 & 0.20 & -0.10 \\
\hline
\end{tabular}

pattern, with the lowest fat concentration occurring during mid-summer when temperatures are greatest.

In the current study, the effect of heat stress was compared with the annual rhythm using an F-test that tested the fit of a model testing the main effect of maximum daily temperature, to a model testing the linear form of the cosine function. Milk, fat, and protein yields were better predicted by the annual rhythm than by maximum temperature in all regions examined. Furthermore, the annual rhythm was a better predictor of fat and protein concentrations in MN, PA, and TX. In FL, however, fat and protein concentrations were better predicted by maximum temperature. This may occur because cows in FL have lower amplitude annual rhythms than those from other states and the variability in environmental temperature may have a greater influence on production. Importantly, maximum temperature follows a similar yearly pattern to absolute day length (Figure 3A and 3C). As discussed below, absolute day length frequently entrains annual rhythms in other species. Therefore, it is impossible to separate the confounding effects of maximum temperature and absolute day length on the annual rhythms of milk and milk component production observational data. Future work could investigate the effect of lighting under controlled environmental conditions to experimentally separate these mechanisms.

The consistency of the annual pattern of milk production among multiple years suggests that it may be represent an underlying endogenous circannual rhythm. Circannual rhythms occur in a wide variety of organisms as a mechanism to predict and adapt to seasonal changes in the environment before they occur (Lincoln, 2019). These rhythms are controlled by endogenous circannual oscillators that detect time-of-year cues from the environment (photoperiod, social stimuli, and nutritional cycles) to influence physiology and behavior across the year (Lincoln et al., 2006). Notably, circannual rhythms can persist for long periods of time after organisms are placed in constant conditions (Pengelley et al., 1976; Gwinner, 2003). Circannual rhythms are commonly involved in optimizing reproductive processes to improve the likelihood of offspring survival.
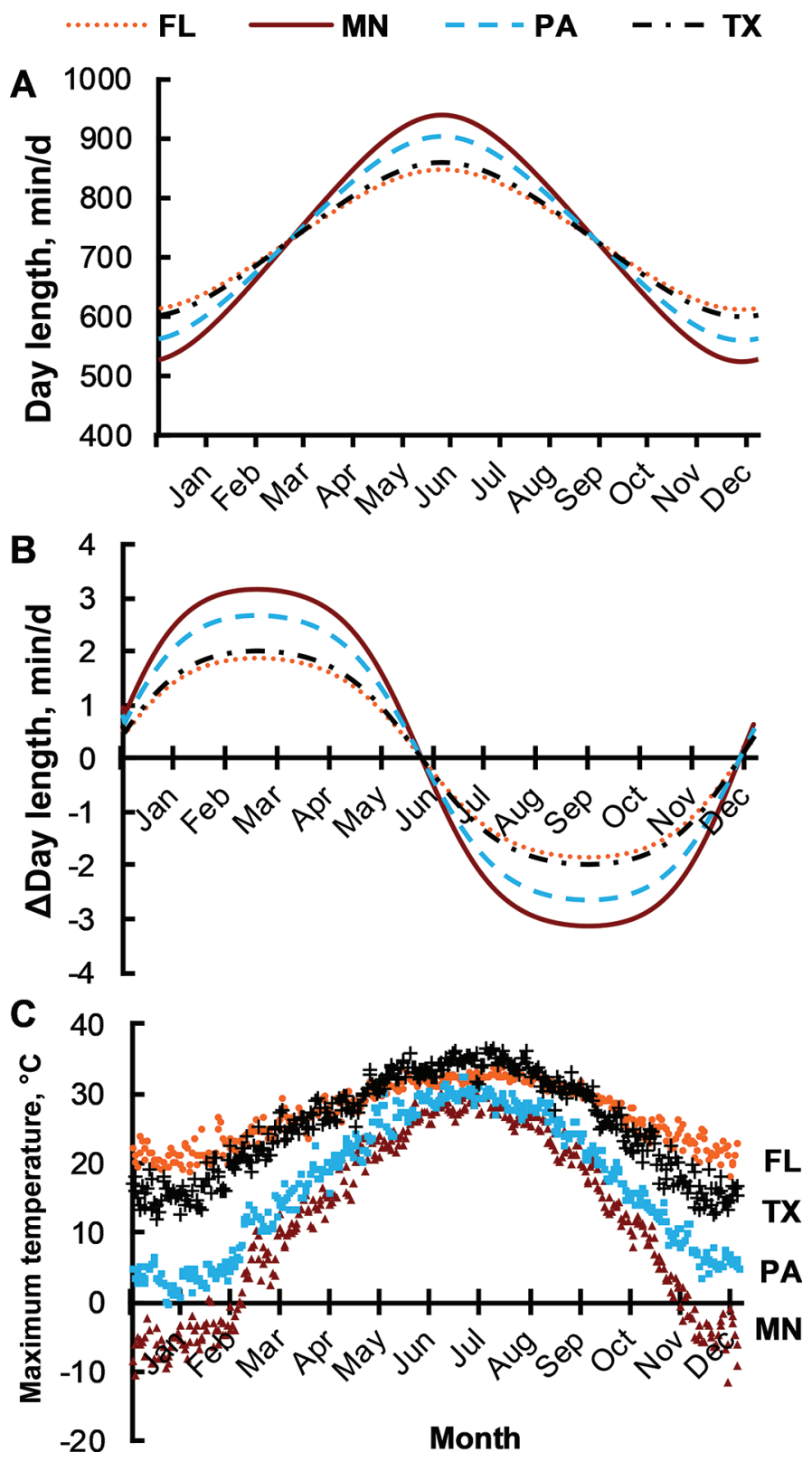

Figure 3. Annual pattern of day length, daily change in day length, and average maximum temperature (years 2004 to 2016) in representative cities of Florida (FL), Minnesota (MN), Pennsylvania (PA), and Texas (TX). Panels show the (A) day length (min of daylight/d), (B) daily change in day length (difference in day length from previous day, $\min )$, and (C) average maximum temperature $\left({ }^{\circ} \mathrm{C}\right)$ across the year. Data were collected for locations of weather stations centrally located in areas with large dairy populations within each state (Tallahassee, FL: $30.4^{\circ} \mathrm{N}$; Litchfield, MN: $45.1^{\circ} \mathrm{N}$; Harrisburg, PA: $40.3^{\circ} \mathrm{N}$, Abilene, TX: $\left.32.4^{\circ} \mathrm{N}\right)$. Day length of each day of the year at the latitude of each station was acquired from the United States Naval Observatory website (https://www.esrl.noaa.gov/gmd/grad/solcalc/). The change in day length across the year was computed for each region using an equation described by Forsythe et al. (1995). The maximum temperature for each weather station was acquired from the US National Weather Service (https://w2.weather.gov/climate/). 
For example, ewes express estrous only during late fall and early winter, restricting the time of lambing to the spring when forage digestibility is greatest (Shelton and Morrow, 1965). Although dairy cows are not generally considered to be seasonal breeders, Hansen (1985) detected modest effects of season and photoperiod length on postpartum calving interval. As a component of reproduction, lactation may be driven by annual rhythms to provide neonates with nutrient-dense milk during the winter when energetic demands are greatest. Several hormones and metabolites exhibit annual rhythms in dairy cows, providing additional support that metabolism of cows may be regulated by an endogenous annual rhythm. Piccione et al. (2012) discovered that the concentrations of creatinine, triacylglycerides, and BHB have 12-mo rhythms. Moreover, Petitclerc et al. (1983) observed that circulating prolactin displays an annual rhythm that persists even after blinding or pinealectomy. Additionally, short day photoperiods during the dry period increase milk in the subsequent lactation (Auchtung et al., 2005).

The annual rhythm of milk yield and the annual rhythms of fat and protein concentration exhibit different phases. Milk yield peaks near the vernal equinox, which corresponds with the time of the year when the day to day change in photoperiod increases most rapidly (Figure 3B). Alternately, milk fat and protein concentrations peak at about the start of winter when absolute day length is shortest (Figure 3A). In model organisms, circannual rhythms can be entrained by both absolute photoperiod length and rate of change of photoperiod. Siberian hamsters (Phodopus sungorus) display annual rhythms of gonadal regression and molting with different critical day lengths (Duncan et al., 1985). Moreover, the rhythms of antler growth and shedding in sika deer can be synchronized by increasing or decreasing photoperiod (Goss, 1976). These results of the current study suggest that day-to-day change in photoperiod may be the primary signal entraining annual rhythms of milk yield and absolute photoperiod is the primary signal entraining annual rhythms of milk fat and protein concentration. Two separate mechanisms may be responsible for regulating seasonal milk yield and milk component concentrations in response to separate seasonal inputs. Hofman (2004) proposed that individual seasonal responses may each be regulated by their own oscillator, whereas Bartell and Gwinner (2005) suggested that different responses may be regulated by the phase-relationships between 2 oscillators.

Although these environmental variables appear to be plausible inputs to entrain annual rhythms in dairy cows, considerable mechanistic research must be performed to better understand their regulation. Examination of annual rhythms of production in a controlled experiment is complicated by the long time-course required to conduct experiments and by the 9-mo lactation of dairy cows that would conflict with the timing of a rhythm. Controlled lighting experiments that simulate changes in absolute photoperiod and rate of change of the photoperiod may be used to better study the mechanisms underlying circannual rhythms.

A wealth of previous research is available using controlled lighting to study the relationship between absolute photoperiod length and milk synthesis in dairy cattle. Placing cows in long days ( $>12 \mathrm{~h}$ daylight) consistently increases milk yield, with the optimal response occurring with a $16 \mathrm{~h}$ of light: $8 \mathrm{~h}$ of dark photoperiod (Dahl et al., 2000). However, a few interesting contradictions have been observed between the results of studies using artificial photoperiod manipulation and the results of the current study examining the naturally occurring annual rhythm. First, although long-day lighting stimulates milk yield, it does not alter fat and protein concentrations. In the current study, not only are fat and protein concentrations strongly correlated with day length, but the long days are also associated with decreases in fat and protein concentrations. Moreover, milk yield is poorly correlated with day length, but maximal milk yield occurs during the spring, when day length is shorter than $12 \mathrm{~h}$.

The paradox between controlled photoperiod manipulation trials and the annual rhythm of milk yield may be caused by animals becoming photorefractory to artificial long-day lighting. In seasonally breeding mammals such as Suffolk sheep (Ovis aries) and Syrian hamsters (Mesocricetus auratus), exposure to a fixed photoperiod for long periods of time causes a spontaneous reversion to a physiological state expected during the opposite photoperiod (Robinson and Karsch, 1984; Lincoln et al., 2005). In short-day breeding sheep, estrus is inhibited by fixed $8 \mathrm{~h}$ of light:16 h of dark photoperiods, whereas the estrus of long-day breeding hamsters is conversely inhibited by fixed $14 \mathrm{~h}$ of light:10 $\mathrm{h}$ of dark photoperiods. Induction of photorefractoriness requires 4 to $12 \mathrm{wk}$ of a fixed photoperiod before a physiological change, which is consistent with results of long-day lighting experiments, which require $4 \mathrm{wk}$ of adaptation before increased milk yield is observed (Dahl et al., 2000).

Annual rhythms of production create challenges for dairy producers and consultants for benchmarking herd performance and diagnosing low milk fat. Changes in nutrition or management are difficult to isolate from the natural rhythm of production. For example, a diet change in December may appear to increase milk production, but the increase may be due simply to the annual rhythm. Using coefficients derived from the linearized cosine function, we calculated regression equa- 
tions to adjust milk, fat, and protein yields, and fat and protein concentrations for the annual rhythm. These equations fit the data significantly within each state, but some caution may be needed when using these equations because for some of the variables the fit of the relationship is relatively weak (Table 1). However, we believe that the yearly pattern is robust enough that these equations provide value to dairy producers and consultants to remove some of the yearly variation in milk production due to the annual rhythm. The regression equations were used to calculate adjustment factors to rapidly standardize production responses across the year (Supplemental Tables S1 to S4; https://doi .org/10.3168/jds.2019-17362). Adjustment factors can be added to average monthly milk, fat, and protein production to account for the annual rhythm.

\section{CONCLUSIONS}

The milk synthesis of dairy cows exhibits an annual rhythm that is affected by geographical region within the United States. The annual rhythm of milk yield appears to be regulated by the change in day length. Fat and protein concentrations have strong correlations with absolute day length, suggesting that they may be entrained by photoperiod. Although maximum environmental temperature is also highly correlated with fat and protein concentrations, a cosine function with a 12-mo period fits the data better, suggesting a better explanation of the yearly pattern. Fat and protein concentrations closely align with the lengthening and shortening of days, whereas milk yield aligns with the change in day length. These annual rhythms may be driven by endogenous circannual oscillators and may require careful consideration to be influenced through management interventions. Consequently, further research must be conducted to understand the physiological mechanisms governing the annual rhythms of milk synthesis.

\section{ACKNOWLEDGMENTS}

The authors gratefully acknowledge Lydia Hardie (Penn State University) for assistance with statistical analysis and John Clay (DRMS) for providing the DRMS production data. The research was supported in part by Agriculture and Food Research Initiative Competitive Grant no. 2015-67015-23358 and 201668008-25025 from the USDA National Institute of Food and Agriculture (Washington, DC; PI KJH), National Institutes of Health (Bethesda, MD) Training Grant no. GM108563 (IJS), and Penn State University, including USDA National Institute of Food and Agriculture Federal Appropriations under project number PEN04539 and accession number 1000803. The authors have not stated any conflicts of interest.

\section{REFERENCES}

Armstrong, D. V. 1994. Heat stress interaction with shade and cooling. J. Dairy Sci. 77:2044-2050. https://doi.org/10.3168/jds.S0022 $-0302(94) 77149-6$.

Auchtung, T. L., A. G. Rius, P. E. Kendall, T. B. McFadden, and G. E. Dahl. 2005. Effect of photoperiod during the dry period on prolactin, prolactin receptor, and milk production of dairy cows. J. Dairy Sci. 88:121-127. https://doi.org/10.3168/jds.S0022 $-0302(05) 72669-2$

Auldist, M. J., B. J. Walsh, and N. A. Thomson. 1998. Seasonal and lactational influences on bovine milk composition in New Zealand. J. Dairy Res. 65:401-411. https://doi.org/10.1017/ S0022029998002970.

Bailey, K. W., C. M. Jones, and A. J. Heinrichs. 2005. Economic returns to Holstein and Jersey herds under multiple component pricing. J. Dairy Sci. 88:2269-2280. https://doi.org/10.3168/jds .S0022-0302(05)72903-9.

Bartell, P. A., and E. Gwinner. 2005. A separate circadian oscillator controls nocturnal migratory restlessness in the songbird Sylvia borin. J. Biol. Rhythms 20:538-549. https://doi.org/10.1177/ 0748730405281826.

Baumgard, L. H., J. B. Wheelock, S. R. Sanders, C. E. Moore, H. B. Green, M. R. Waldron, and R. P. Rhoads. 2011. Postabsorptive carbohydrate adaptations to heat stress and monensin supplementation in lactating Holstein cows. J. Dairy Sci. 94:5620-5633. https://doi.org/10.3168/jds.2011-4462.

Bourdon, L., A. Buguet, M. Cucherat, and M. W. Radomski. 1995. Use of a spreadsheet program for circadian analysis of biological/ physiological data. Aviat. Space Environ. Med. 66:787-791.

Cornelissen, G. 2014. Cosinor-based rhythmometry. Theor. Biol. Med. Model. 11:16-24. https://doi.org/10.1186/1742-4682-11-16.

Dahl, G. E., B. A. Buchanan, and H. A. Tucker. 2000. Photoperiodic effects on dairy cattle: A review. J. Dairy Sci. 83:885-893. https:/ /doi.org/10.3168/jds.S0022-0302(00)74952-6.

Duncan, M. J., B. D. Goldman, M. N. Di Pinto, and M. H. Stetson. 1985. Testicular function and pelage color have different critical daylengths in the Djungarian Hamster, Phodopus sungorus sungorus. Endocrinology 116:424-430. https://doi.org/10.1210/endo $-116-1-424$.

Forsythe, W. C., E. J. Rykiel Jr., R. S. Stahl, H. Wu, and R. M. Schoolfield. 1995. A model comparison for daylength as a function of latitude and day of year. Ecol. Modell. 80:87-95. https://doi .org/10.1016/0304-3800(94)00034-F.

Glatting, G., P. Kletting, S. N. Reske, K. Hohl, and C. Ring. 2007. Choosing the optimal fit function: Comparison of the Akaike information criterion and the F-test. Med. Phys. 34:4285-4292. https:/ /doi.org/10.1118/1.2794176.

Goss, R. J. 1976. Photoperiodic control of antler cycles in deer. III. Decreasing versus increasing day lengths. J. Exp. Zool. 197:307-312. https://doi.org/10.1002/jez.1401970302.

Gwinner, E. 1996. Circadian and circannual programmes in avian migration. J. Exp. Biol. 199:39-48. https://doi.org/10.1098/rspb .2009.2112.

Gwinner, E. 2003. Circannual rhythms in birds. Curr. Opin. Neurobiol. 13:770-778. https://doi.org/10.1016/j.conb.2003.10.010.

Hansen, P. J. 1985. Seasonal modulation of puberty and the postpartum anestrus in cattle: A review. Livest. Prod. Sci. 12:309-327. https://doi.org/10.1016/0301-6226(85)90131-9.

Hazlerigg, D., D. Lomet, G. Lincoln, and H. Dardente. 2018. Neuroendocrine correlates of the critical day length response in the Soay sheep. J. Neuroendocrinol. 30:e12631. https://doi.org/10.1111/jne .12631 .

Hofman, M. A. 2004. The brain's calendar: Neural mechanisms of seasonal timing. Biol. Rev. Camb. Philos. Soc. 79:61-77. https://doi .org/10.1017/S1464793103006250. 
Lincoln, G. 2019. A brief history of circannual time. J. Neuroendocrinol. 31:e12694. https://doi.org/10.1111/jne.12694.

Lincoln, G., I. Clarke, R. Hut, and D. Hazlerigg. 2006. Characterizing a mammalian circannual pacemaker. Science 314:1941-1944. https: //doi.org/10.1126/science.1132009.

Lincoln, G., J. D. Johnston, H. Andersson, G. Wagner, and D. G. Hazlerigg. 2005. Photorefractoriness in mammals: Dissociating a seasonal timer from the circadian-based photoperiod response. Endocrinology 146:3782-3790. https://doi.org/10.1210/en.2005-0132.

Loudon, A. S. I., and J. D. Curlewis. 1988. Cycles of antler and testicular growth in an aseasonal tropical deer (Axis axis). J. Reprod. Fertil. 83:729-738. https://doi.org/10.1530/jrf.0.0830729.

Pengelley, E. T., S. J. Asmundson, B. Barnes, and R. C. Aloia. 1976. Relationship of light intensity and photoperiod to circannual rhythmicity in the hibernating ground squirrel, Citellus lateralis. Comp. Biochem. Physiol. A Comp. Physiol. 53:273-277. https:// doi.org/10.1016/S0300-9629(76)80035-7.

Petitclerc, D., R. R. Peters, L. T. Chapin, W. D. Oxender, K. R. Refsal, R. K. Braun, and H. A. Tucker. 1983. Effect of blinding and pinealectomy on photoperiod and seasonal variations in secretion of prolactin in cattle. Proc. Soc. Exp. Biol. Med. 174:205-211. https://doi.org/10.3181/00379727-174-41726.

Piccione, G., V. Messina, S. Scianó, A. Assenza, T. Orefice, I. Vazzana, and A. Zumbo. 2012. Annual changes of some metabolical parameters in dairy cows in the Mediterranean area. Vet. Arh. 82:229-238.

Rhoads, M. L., R. P. Rhoads, M. J. VanBaale, R. J. Collier, S. R. Sanders, W. J. Weber, B. A. Crooker, and L. H. Baumgard. 2009. Effects of heat stress and plane of nutrition on lactating Holstein cows: I. Production, metabolism, and aspects of circulating somatotropin. J. Dairy Sci. 92:1986-1997. https://doi.org/10.3168/ jds.2008-1641.

Robinson, J. E., and F. J. Karsch. 1984. Refractoriness to inductive day lengths terminates the breeding season of the Suffolk ewe. Biol. Reprod. 31:656-663. https://doi.org/10.1095/biolreprod31.4 .656 .

Rungruang, S., J. L. Collier, R. P. Rhoads, L. H. Baumgard, M. J. de Veth, and R. J. Collier. 2014. A dose-response evaluation of rumen-protected niacin in thermoneutral or heat-stressed lactat- ing Holstein cows. J. Dairy Sci. 97:5023-5034. https://doi.org/10 3168/jds.2013-6970

Salfer, I. J., C. D. Dechow, and K. J. Harvatine. 2019. Annual rhythms of milk and milk fat and protein production in dairy cattle in the United States. J. Dairy Sci. 102:742-753. https://doi.org/10.3168/ jds.2018-15040.

Shelton, M., and J. T. Morrow. 1965. Effect of season on reproduction of Rambouillet ewes. J. Anim. Sci. 24:795-799. https://doi.org/10 $.2527 /$ jas $1965.243795 \mathrm{x}$

Shwartz, G., M. L. Rhoads, M. J. VanBaale, R. P. Rhoads, and L. H. Baumgard. 2009. Effects of a supplemental yeast culture on heatstressed lactating Holstein cows. J. Dairy Sci. 92:935-942. https:/ /doi.org/10.3168/jds.2008-1496.

West, J. W. 2003. Effects of heat-stress on production in dairy cattle. J. Dairy Sci. 86:2131-2144. https://doi.org/10.3168/jds.S0022 $-0302(03) 73803-\mathrm{X}$

Wheelock, J. B., R. P. Rhoads, M. J. VanBaale, S. R. Sanders, and L. H. Baumgard. 2010. Effects of heat stress on energetic metabolism in lactating Holstein cows. J. Dairy Sci. 93:644-655. https://doi .org/10.3168/jds.2009-2295.

Wood, P. D. P. 1970. A note on the repeatability of parameters of the lactation curve in cattle. Anim. Prod. 12:535-538. https://doi.org/ 10.1017/S0003356100029135.

Woodfill, C. J., J. E. Robinson, B. Malpaux, and F. J. Karsch. 1991. Synchronization of the circannual reproductive rhythm of the ewe by discrete photoperiodic signals. Biol. Reprod. 45:110-121. https: //doi.org/10.1095/biolreprod45.1.110.

Zimbelman, R. B., L. H. Baumgard, and R. J. Collier. 2010. Effects of encapsulated niacin on evaporative heat loss and body temperature in moderately heat-stressed lactating Holstein cows. J. Dairy Sci. 93:2387-2394. https://doi.org/10.3168/jds.2009-2557.

\section{ORCIDS}

I. J. Salfer (ํ) https://orcid.org/0000-0001-5895-8172

P. A. Bartell (1) https://orcid.org/0000-0002-0640-2604

C. D. Dechow (1) https://orcid.org/0000-0002-9012-2807

K. J. Harvatine @ https://orcid.org/0000-0001-6422-2647 